\title{
Cidades e políticas públicas
}

\author{
Ana Lúcia Coelho Heckert, ${ }^{I, \star}$ Maria Elizabeth Barros de Barros, I Silvia Vasconcelos Carvalho ${ }^{I I}$ \\ ${ }^{I}$ Universidade Federal do Espírito Santo, Vitoria, ES, Brasil \\ ${ }^{\text {II }}$ Universidade Federal Fluminense, Niterói, RJ, Brasil
}

\begin{abstract}
Resumo
O artigo apresenta o tema da cidade no contemporâneo e objetiva discutir e analisar a importância da produção de políticas públicas e, portanto, implicadas com a participação social na elaboração, execução e monitoramento dos espaços urbanos. Afirma a diferença entre estas e as politicas de governo voltadas para conter as insatisfações e tensões urbanas. Destaca também questões e problemas urbanos emergentes na atualidade, tais como a violência, a superpopulação, a escassez de moradias, insistindo no direito à cidade, na produção coletiva de modos de vida e no questionamento dos modos de governamentalização da vida que estão na cena urbana.
\end{abstract}

Palavras-chave: cidades; políticas públicas; processos de subjetivação.

\section{Cities and public policies}

\begin{abstract}
The article presents the theme concerning the contemporary city and, therefore, aims to discuss and analyze the importance of the production of public policies involved with social participation in the formulation, implementation and monitoring of urban spaces. It states the difference between urban spaces and government policies, which are focused to contain dissatisfactions and urban tensions. It also highlights matters and urban issues emerging today, such as violence, overcrowding and housing shortages, insisting on the right to the city, on the collective production of modes of life and also on questionings about life governmentalisation modes that are in urban scene.
\end{abstract}

Keywords: city; public policy; subjective processes.

"Pobres são os mais atingidos pela poluição urbana" (SALDIVA apud HARARI; CRISTI, 2012, online). Assim tem início uma matéria recentemente noticiada na mídia brasileira. Paulo Saldiva, professor da Faculdade de Medicina da USP, especialista em poluição atmosférica, ao ser entrevistado pela revista Carta Maior, afirma que o que impede as metrópoles de reduzirem a emissão de poluentes são motivos políticos e interesses econômicos. "O fato de tratarmos o solo das cidades como mercadoria faz a população mais pobre migrar para áreas mais acessíveis na periferia, aumentando o tempo de permanência no tráfego", diz Saldiva (apud HARARI; CRISTI, 2012, online). A matéria traz, ainda, dados da Organização Mundial da Saúde (OMS) segundo os quais, cerca de 1,3 milhão de mortes por ano no mundo são causadas pela poluição urbana. Só em São Paulo morrem 4 mil por ano, diz a matéria. Indica, também, outro dado alarmante: o aumento surpreendente de 2,9 mil mortes em 2004, quando o número de carros ainda era um terço menor do que o atual. Os principais atingidos foram idosos, crianças, gestantes, portadores de doenças respiratórias e cardíacas crônicas e, principalmente, os mais pobres.

Segundo Paulo Saldiva (apud HARARI; CRISTI, 2012, online) "[...] não há impedimentos técnicos ou falta de conhecimento para que esse problema seja resolvido. No meu entendimento, temos todas as condições de resolver o problema da poluição do ar em nossas cidades em alguns anos".

\footnotetext{
^Endereço para correspondência: Universidade Federal do Espírito Santo, Departamento de Psicologia, Departamento de Psicologia. Avenida Fernando Ferrari s/no - Goiabeiras - Vitoria, ES - Brasil. CEP: 29060-900.E-mail: ana.heckert@ gmail.com, betebarros@uol.com.br, silviacj@superig.com.br
}

O patologista indicou duas causas fundamentais do problema: o caráter segregador da ocupação do solo nas metrópoles e a falta de políticas públicas que privilegiem o transporte público. De acordo com a OMS, os elevados níveis de poluição na cidade de São Paulo são responsáveis pela redução da expectativa de vida em cerca de um ano e meio. Afirma, ainda, que quem mais polui são os carros, e, nas grandes cidades do Brasil, a opção pelo transporte veicular sequer traz o benefício de uma mobilidade eficiente. "A existência de um transporte coletivo rápido, eficiente e barato daria a motivação para que a população migrasse para o transporte público", afirma Saldiva (apud HARARI; CRISTI, 2012, online).

Em outra matéria (OTÁVIO, 2012), agora na cidade do Rio de Janeiro, a juíza Maria Teresa Gazineu, titular da segunda vara de Fazenda Pública do Tribunal de Justiça do Rio de Janeiro, o tema são as obras de reurbanização do morro da Providência, localizado entre a estação férrea Central do Brasil e a zona portuária. A matéria nos traz importantes informações sobre o morro no que se refere aos laços com a história da cidade e do país. Conforme o articulista, sua ocupação data de fins do século XIX, após soldados que voltavam da guerra de Canudos (1896-1897) verem descumprida a promessa do governo federal de dar-lhes residência legalizada nas imediações do Centro. A palavra Favela teria nascido ali, já que os ex-soldados faziam referência ao local com o mesmo nome de um morro que foi palco de batalhas no interior da Bahia, assim batizado a partir de sua vegetação. Praticamente abandonado durante grande parte do século XX e começo do XXI, quando em 2008 foi palco de violenta ocupação por tropas militares federais para tentar estancar as batalhas pelo comando do tráfico 
de drogas e pavimentar o caminho para a instalação de uma Unidade de Polícia Pacificadora (UPP), carro-chefe da política de segurança do atual governo do estado. O morro da Providência encontra-se no meio do caminho das reformas urbanísticas que forjam o Rio do século XXI a partir de eventos internacionais como a Copa do Mundo de 2014 e a Olimpíada de 2016. A matéria termina nos lembrando uma anedota sobre o ex-jogador de futebol Garrincha, que após ouvir um plano perfeito do treinador para eliminar o adversário interrompeu a empolgação geral e perguntou, "Tudo bem, mas combinou com o lado de lá?". "A prefeitura parece também ter se esquecido de parte importante do projeto, os moradores, pelo menos no que diz respeito à execução das obras e a remoção de moradias" (OTÁVIO, 2012, online).

Guattari (1992) caminha nessa direção em suas análises sobre as cidades no contemporâneo nos convocando a pensar estratégias urbanísticas que se constituam em outra direção ético-política. Em "Restauração da cidade subjetiva", Guattari (1992, p. 172) afirma que vivemos um "drama urbanístico" que sinaliza uma crise que envolve o futuro da espécie humana no planeta e nos indica a urgência de uma reorientação radical dos meios e finalidades de produção no campo social, que implica uma inflexão da industrialização e

[...] uma limitação da circulação de automóveis ou a invenção de meios de transportes não poluentes, e o fim dos grandes desflorestamentos [...]. Ele ainda destaca que esse processo inclui, necessariamente, uma mudança de mentalidades e dos hábitos coletivos, delineando-se, portanto, uma inflexão radical nos modos de produção subjetiva hegemônicos hoje. Destaca que as problemáticas urbanas são meio de produção de subjetividade, o que implica que não é mais possível que os urbanistas pensem as cidades apenas em termos de espacialidade, uma vez que o "[...] fenômeno urbano mudou de natureza (GUATTARI, 1992, p. 173).

Segundo Guattari (1992, p. 172, grifo do autor),

As cidades são imensas máquinas - megamáquinas, para retomar a expressão de Lewis Mumford - produtoras de subjetividade individual e coletiva. O que conta com as cidades hoje, é menos os seus aspectos de infraestrutura, de comunicação e de serviço do que o fato de engendrarem, por meio de equipamentos materiais e imateriais, a existência humana sob todos os aspectos que se queira considerá-la.

Essas são pistas importantes que Guattari (1992) nos indica para o propósito desse texto: pensar o modo como as políticas públicas se forjam hoje no contemporâneo no que diz respeito a experimentação de um novo urbanismo modo de lidar com a questão das cidades. $\mathrm{Na}$ esteira do autor, entendemos que é importante pensar em transformações políticas, o que não pode ocorrer sem uma mutação de "mentalidades" nos modos de produção de subjetividade. Encontramo-nos, portanto, diante de um círculo de dupla direção. "Uma ordem objetiva 'mutante' pode nascer do caos atual de nossas cidades e também uma nova poesia, uma nova arte de viver" (GUATTARI, 1992, p. 175). Como pensar as políticas públicas que ordenam as cidades hoje? Como produzir conexões entre os modos de fazer andar a vida nas cidades e as políticas que as administram? Como pensar as cidades a partir de políticas efetivamente públicas, ou seja, que implicam participação social em sua elaboração, planejamento, execução, monitoramento?

\section{Intervenções fabricando outras paisagens na cidade}

Nas primeiras décadas do século XIX, Londres e Paris conviviam com um impressionante crescimento demográfico, efeito do êxodo maciço da população do campo atraída pelo processo de industrialização em curso nessas cidades. Multidões de pessoas circulavam por suas ruas, produzindo um novo cenário que, por sua vez, suscitava nova ordem de questões.

Sobre essas cidades se debruçavam pensadores, filósofos, escritores e médicos com o fim de propor soluções não mais para problemas pontuais da cidade, mas para dar conta desse espaço urbano emergente que se colocava em relação de descontinuidade, de ruptura, com seu passado e que se transformava, ele mesmo, em problema. Descreviam essas cidades como lugares onde tudo era imundície e miséria e onde milhões de mulheres e crianças se amontoavam em cubículos, construídos em pátios sombrios, sem ar e sem luz. Falavam de casebres e casas que praticamente se atropelavam umas às outras, e se agrupavam em torno de monumentos que glorificavam a história da civilização. "Paris é o casamento do luxo e da miséria: esse é o complemento do quadro" (CHOAY, 1965, p. 78).

As soluções apontadas por esses críticos apresentavam alguns pontos em comum dirigidos para a ordenação, sistematização, e classificação dos espaços e bairros urbanos: Owen (1771-1858) sugeriu o melhoramento das habitações e sua alocação em cidades-modelo cercadas de espaços verdes; Fourier (1772-1837) propôs a Teoria Falangista que postulava a integração do campo com a cidade pela racionalização e classificação sistemática dos lugares e das atividades. Cabet (1788-1856) propôs uma cidade onde os bairros seriam bem diferenciados e classificados, os prédios pintados de cores diferentes de acordo com sua finalidade e natureza: vermelho para os grandes prédios, azul para as oficinas, violeta para os monumentos, e as ruas devendo ter 16 casas de cada lado, com um edifício público no meio. Estabeleceu também locais específicos para assembleias populares (CHOAY, 1965).

Se essas propostas nunca chegaram a se efetivar em projetos definidos, as repercussões das transformações tecnológicas, econômicas, políticas e demográficas ocorridas mudaram não só o perfil físico e social das cidades, mas produziram novos sistemas de idéias e de articulação de conceitos para nomear essa configuração emergente (PECHMAN, 1994).

Antigos problemas relativos à moradia, às epidemias, à miséria e ao desemprego tiveram de ser redimensionados, com a invenção de instrumentos que esquadrinharam, recortaram e transformaram a cidade em "objeto de saber". A antropologia, a sociologia, a psicologia, a demografia, a arquitetura e o urbanismo, foram os saberes emergentes que se juntaram à medicina 
para dar conta do "urbano", que aparece como um conceito quando a cidade se torna um tema em si mesma, e remete, não à sua materialidade somente, mas a uma síntese que vai pretender dar conta das novas formas de conhecer e intervir no campo social (PECHMAN, 1994).

Segundo Fourquet e Murard (1978) a organização dessas cidades, impulsionada pela industrialização crescente, foi concebida à imagem de um equipamento coletivo de "disciplina", fixação e de supervisão. Com isso os autores indicam que a cidade captura as forças materiais e fluidas das multidões para fixá-las no campo social e territorial no que ele denomina como equipamentos coletivos de poder: a escola, o hospital, a prisão e as casas domiciliares, alinhando-se com Foucault quando este alerta para o modo de organização da vida em que o espaço é esquadrinhado e conectado de modo a intensificar a disciplinarização da vida que ele denomina como dispositivo disciplinar.

A fábrica não exclui os indivíduos; liga-os a um aparelho de produção. A escola não exclui os indivíduos; mesmo fechando-os; ela os fixa a um aparelho de transmissão de saber. O hospital psiquiátrico não exclui os indivíduos, liga-os a um de correção e normalização (FOUCAULT, 1996, p. 114).

Essas instituições "disciplinares" funcionarão como modelos universais a serem aplicados em qualquer outro tipo de equipamento ou dispositivo de poder, como sistemas rígidos e fechados de inclusão e normalização, codificados em regras e normas institucionalizadas e devidamente supervisionadas (FOURQUET; MURARD, 1978).

Em decorrência de tais processos esta cidade industrial produziu aparatos que operavam por meio de repartições/disjunções em cadeia, com as quais a massa populacional era avaliada e alocada no espaço social:

Uma série de alternativas fechadas, de disjunções rígidas, determinantes de espaços fragmentados, limitados e, por vezes, espaços de exclusão: família/sociedade civil, público/privado, saudável/doente, doente físico/doente mental, trabalhador/sem trabalho, operário/vagabundo; crianças normais/ crianças desadaptadas (FOURQUET; MURARD, 1978, p. 76).

$\mathrm{O}$ habitante da cidade industrial era reconhecido em função dos serviços coletivos e materiais em que estavam inscritos: se trabalha, está na fábrica; se é doente mental, está no manicômio; se é criança, está na escola; se é doente, está no hospital; se é velho, está no asilo. Se não está inscrito em nenhum desses lugares, certamente está em lugar nenhum, engrossando as filas que se formam no exterior das fábricas, andando sem destino pelas ruas, morando em lugares onde não se deve morar, não comendo o que se precisa comer. Para estes, “[...] foi necessário inventar a criminalidade" (FOURQUET, MURARD, 1978, p. 73).

Segundo Foucault (1979, p. 288), a emergência de tal população urbana industrial como objeto de estudo está ligada à mudança, na Europa, na forma de governo da época, não mais centrada no quadro jurídico da soberania, mas voltada para uma arte de governar, esta vinculada ao desenvolvimento de uma ciência econômica que possibilitou circunscrever a especificidade dos problemas ligados à população: seu funcionamento próprio, sua regularidade e seus deslocamentos a partir do conhecimento do número de mortes, de nascimentos, das doenças, dos fluxos de trabalho, de riqueza e dos efeitos econômicos que produziam.

Nesse contexto a estatística é transformada em importante instrumento para a análise e controle desses fenômenos populacionais, contribuindo para a ciência/ arte política de governo que, de posse de tal conhecimento, visa governar essa população, aumentar sua saúde, sua riqueza, gerir seu curso, administrar seus movimentos por meio de táticas e técnicas, circunscrevendo um novo poder - a biopolítica.

Tal poder, todavia, não vai dispensar o dispositivo disciplinar. ${ }^{1}$ Ao contrário, este será valorizado e reforçado para além de seus objetos e objetivos iniciais que se aplicavam aos corpos no interior dos espaços fechados - a casa, a escola, o quartel, as oficinas, os hospitais, o exército -, formando um quadro de gestão que vai se acoplar com uma tecnologia regulamentadora, que realoca esses corpos nos processos biológicos coletivos, a tecnologia biopolítica. Esta não exclui aquela, mas se compõe com ela: o conhecimento gerado a partir dos corpos fixados, disciplinados e normalizados se articula com os mecanismos reguladores e incidirão sobre a população, retificando seu curso, seu peso, sua forma (FOUCAULT, 1999).

De modo a tornar mais clara essa composição entre os mecanismos disciplinadores, formadores das normas e os regulamentadores da biopolítica, Foucault (1999, p. 299) dá o exemplo das cidades operárias. De um lado, articulações disciplinares: a disposição espacial da cidade, com a separação entre espaço público e espaço privado e a localização espacial das construções, cada uma com sua função específica (as casas, os negócios, as oficinas e outros); a organização interna das casas - cada indivíduo em seu lugar, em seu cômodo; a normalização dos comportamentos - o papel da mãe de família, do pai, o lugar do filho. De outro, perpendicular a este, os mecanismos regulamentadores, incidindo sobre o conjunto populacional: as campanhas de insistência na poupança para a compra e manutenção de moradias, para os seguros de saúde e as aposentadorias, as regras preventivas coletivas para assegurar a saúde, prolongar a vida útil de trabalho, as políticas da natalidade, de educação, voltadas para o cuidado e a conservação das crianças e adolescentes. E também a numeração obrigatória das casas, o controle das carruagens e a fotografia, que possibilitava o registro dos habitantes dessa cidade.

${ }^{1}$ Em Foucault (1979, p. 244) dispositivo é “[...] um conjunto decididamente heterogêneo que engloba discursos, instituições, organizações arquitetônicas, decisões regulamentares, leis, medidas administrativas, enunciados científicos, proposições filosóficas, morais, filantrópicas. Em suma, o dito e o não dito são os elementos do dispositivo. O dispositivo é a rede que se pode estabelecer entre estes elementos". Nesta discussão o dispositivo disciplinar diz respeito ao processo de esquadrinhamento que delimita de modo claro e preciso o lugar e o sentido político de cada instituição, focalizando o indivíduo e o controle do seu corpo. O dispositivo disciplinar funciona por meio de estratégias como a concentração e a distribuição no espaço, a ordenação do tempo, a sanção normalizadora. 
$\mathrm{Na}$ organização dessa cidade/objeto, o projeto de intervenção no espaço urbano não se deu a partir de nenhum dos autores citados anteriormente, mas veio pelas mãos do Barão Haussman, com uma iniciativa que transformou a configuração urbana de Paris da segunda metade do século XIX e se difundiu para outras capitais européias, chegando ao Brasil no início do século XX, capitaneada à época pelo prefeito do Rio de Janeiro, Pereira Passos (BENCHIMOL, 1992).

$\mathrm{Na}$ ocasião em que Pereira Passos assumiu a Prefeitura da cidade, o Rio de Janeiro, com sua estrutura de cidade colonial, possuía quase um milhão de habitantes mal servidos por redes de transportes e de esgoto, de abastecimento de água e de programas de saúde e segurança. Na região central - a Cidade Velha e adjacências - eclodiam habitações coletivas, os cortiços, epidemias de febre amarela, varíola, cólera, conferindo à cidade a fama internacional de porto sujo ou "cidade da morte", como se tornara conhecida.

A reforma urbana de Pereira Passos, período conhecido popularmente como "Bota-abaixo", visou o saneamento, a urbanização e o embelezamento, a fim de conceder ao Rio de Janeiro ares de cidade moderna e cosmopolita.

O prefeito, médico sanitarista e filho do Barão de Guaratiba, presenciou a remodelação proposta por Haussman, tomou Paris como modelo e propôs uma série de modificações, como a modernização da zona portuária, o aterro de pequenas enseadas, a abertura de ruas amplas e largas avenidas, das quais a mais famosa foi a Avenida Central, hoje Avenida Rio Branco, que deveria ser margeada de ambos os lados por prédios elegantes e artísticos, segundo um padrão definido de construção. Criou e impôs, igualmente, uma extensa lista de leis draconianas de modo a disciplinar a vida social, o que redundou em um mecanismo inibidor e seletivo do livre trânsito dos moradores pela cidade - as posturas municipais (BENCHIMOL, 1992).

Em seu conjunto, as mudanças urbanísticas projetadas atendiam a dois objetivos complementares: $\mathrm{o}$ primeiro dizia respeito à circulação urbana de veículos, mercadorias e pessoas; o segundo, à transferência de um espaço densamente povoado por um contingente de pessoas de origens e extrações sociais diversas, repleto de casas de cômodos e cortiços, para outro grupo de proprietários, aos quais caberia edificar os novos prédios que embelezariam a Avenida.

Esses projetos promoveram um favorecimento da vida das camadas mais ricas da população e o "exílio" de ex-escravos, operários e assalariados sobre quem recaiu o ônus da modernização. Esse contingente de pessoas, além de ter perdido suas moradias, teve que abandonar suas ocupações no mercado informal de trabalho, desenvolvido, na maioria das vezes, nas ruas da cidade. Os vendedores ambulantes, os condutores de transportes de tração animal, os vendedores dos quiosques, os engraxates, os carroceiros, as lavadeiras, vendedoras de doces e outros quitutes, e outros, foram expulsos das vias públicas nas áreas reurbanizadas por Pereira
Passos, gerando a idéia de que a miséria e a desigualdade social haviam deixado de existir, quando o que houve foi um reforço da rígida estratificação do campo social (ARAÚJO, 1993, p. 233).

A estratégia utilizada pelos médicos, urbanistas e arquitetos para a redefinição da ordem social nesse período teve como base a reorganização disciplinar e higienista da cidade, fundada na "estabilidade", na "fixação" e na "homogeneidade". Entretanto, a "haussmanização", ou seja, o evisceramento dos bairros centrais das grandes capitais, não obteve o resultado desejado em relação à questão de habitação das massas populares. Ao lado da cidade idealizada uma outra continuava existindo: a racionalidade urbana viu-se perturbada pela "desordem" de uma área que, apesar dos mecanismos oficiais, voltava à cena: os pardieiros, as moradias populares, as casas de cômodos que ressurgiam de imediato em outras partes, na busca de uma solução que garantisse a proximidade do local de trabalho com o lugar da moradia.

Esses trabalhadores encontraram também outra solução: apoiados em uma legislação que proibia a construção de casebres nas regiões saneadas da cidade, mas que era fluida e imprecisa em relação às encostas dos morros, ergueram suas casas nas fraldas dos morros existentes em todas as regiões da cidade (BENCHIMOL, 1992), assim como outros se deslocaram para as zonas suburbanas, que se transformaram em locais superpopulosos, construindo outras cidades.

Nestes espaços essa população desqualificada resistia em seus costumes, religiões, músicas e danças, sempre observada de perto pela polícia republicana que se tornou um aparelho altamente poderoso e importante, cabendo a ela impedir toda e qualquer espécie de desordem, quer fossem movimentos individuais ou coletivos de transgressão. Sob o lema da "garantia das liberdades individuais", reprimiam movimentos associativos de qualquer espécie: políticos, religiosos, sociais, recreativos, circunstanciais ou individuais (crimes comuns ou de contravenção) (NADER, 1994).

Entre vários de seus efeitos, as regulamentações resultantes desta tecnologia produziram uma maneira de separar, no interior de uma população, uns grupos em relação aos outros. Elas engendraram cortes, rupturas no conjunto populacional ao qual se dirigiam e, sustentadas em sua quase totalidade por conhecimentos e procedimentos oriundos das ciências biológicas na vertente do darwinismo social, justificaram a desqualificação desses grupos de pobres, negros, mestiços, mulatos como seres inferiores, "os sem direito à cidade". Como não se enquadram em nenhum dos equipamentos de fixação coletiva referidos acima, "ficam à margem", e são a expressão clara do lema biopolítico: "[...] fazer viver e deixar morrer" (FOUCAULT, 2009).

Recuperar essas histórias passadas são importantes. Não para demonstrar relações de causa e efeito entre passado e presente, mas para nos apresentar problemas com os quais ainda estamos relacionados. $\mathrm{O}$ "acontecimento favela", bem como os moradores pobres 
da cidade remodelada, são nossos contemporâneos e se apresentam para nós no crescimento explosivo, em nível mundial, do número de favelas construídas nos morros, sobre palafitas nas margens de rios, lagoas e valões onde são despejados os dejetos e lixo urbanos. Compõem, com os "sem teto", o que Davis (2006) denomina como "Planeta Favela".

Nestes últimos tempos as favelas brasileiras, além de abrigar trabalhadores que não tem condições de pagar por moradias em outros lugares, servem igualmente de abrigo para os centros de tráfico de drogas que impõem regimes de terror e de controle aos seus moradores. São também consideradas como o foco irradiador da violência urbana que aparece sob a forma da chamada "delinquência infanto-juvenil" e da "bandidagem adulta", que se alastra pela cidade a qual, por sua vez, exige intervenções drásticas para conter o que se denomina como violência urbana.

Ainda de acordo com Davis (2006, p. 200), a população favelada mundial, cresce "[...] espantosos 25 milhões de pessoas por ano [...]", tornando-se uma questão encampada pela ONU, FMI e Banco Mundial, preocupados com as Metas de Desenvolvimento mundial do Milênio. A partir de pesquisas e relatórios dessas agências e do fracasso de Conferências realizadas pela ONU em propor soluções para esse problema geopolítico, o Pentágono americano criou grupos de "Operações Militares em Terreno Urbanizado", treinados para um combate prolongado para dominar a luta nas ruas sob condições realistas de favelas nas cidades do terceiro mundo: "[...] as forças de segurança deveriam abordar o fenômeno sociológico das populações excluídas" (DAVIS, 2006, p. 200).

Metamorfoses da chamada questão social vêm se efetuando de modo alterar as paisagens da maioria das cidades brasileiras. Nas palavras de Telles (2010), uma complexa trama social é tecida e esta não cabe em modelos dualistas de análise e escapa ao que os indicadores sociais identificam como zonas de vulnerabilidade social.

É nessas tramas que os lances da vida são jogados, é aí que se processam as exclusões, as fraturas, os bloqueios e também as capturas na hoje extensa e multifacetada malha de ilegalidades que perpassam a cidade inteira e que operam, também elas, como tantas outras formas de junção e conjugação da trama social [...]. No meio, quer dizer, em tudo o que importa, não existe o vazio que expressões como a de exclusão social podem sugerir, mas os fios que tecem a tapeçaria do mundo social, as tramas da cidade, e nas quais estão em jogo os sentidos da vida e das formas de vida (TELLES, 2010, p. 198).

Outra "ordem de problemas" emerge nas últimas décadas do século XX, segundo aponta Telles (2010) a partir das contribuições de Agamben acerca das conexões entre Estado de Exceção e vida nua. E, neste conjunto de problemas, podemos incluir a degradação dos espaços públicos, a violência das forças repressivas estatais, a domesticação dos movimentos e coletivos pela via do empreendedorismo estatal, os efeitos da agenda neoliberal, dentre outros, desenhando outros modos de circulação e ocupação das cidades. A participação e a reivindicação "dentro da ordem democrática" encapsulam os direitos sociais e políticos e a participação na gestão da cidade, via políticas públicas, nas malhas do já pensado, do já permitido, do suportável para os limites da ação estatal, do realismo das escolhas possíveis, do consenso efetuado entre alguns poucos.

Mas, como aponta Mizoguchi (2012, p. 53), muitas operações atualizam-se na superfície das cidades; “[...] modulações das modulações dos modos de existência fascismos, multiplicidades, poderes e estilos contemporâneos pondo-se em infindos embates". E é neste campo de questões que as políticas públicas são reivindicadas e se tornam objeto de indagação por parte da população.

\section{Entre políticas de governo e políticas públicas: pensando as cidades}

No nosso entendimento, para avançar no debate acerca das articulações entre políticas públicas e um novo urbanismo é necessário definir algumas diretrizes que nos ajudem nesse processo, como por exemplo, o conceito de política e de política pública.

No dicionário de política da UnB, Norberto Bobbio et al. (2002) nos oferece uma definição de política derivada de polis (politikós), que diz respeito a tudo o que se refere à cidade. Segundo o autor, já em Aristóteles, na sua obra Política, encontramos uma concepção de política que se refere à natureza, funções e divisão do estado, assim como às várias formas de governo. Política como arte ou ciência de governar e de reflexão nas cidades. Política como polis, arte e ciência de governar, o Estado compareceria como um de seus aspectos (BARROS, R.; PASSOS, 2009).

$\mathrm{Na}$ modernidade o termo política designa a atividade ou conjunto de atividades que têm como referência a polis, entendido como o Estado. Em todas as suas modulações o que se mantém é a idéia de política como uma atividade ou práxis humana, poder político como exercício de poder. Diferente do poder despótico, que se exerce pelo interesse do senhor, o poder político se exerceria pelo interesse de quem governa e de quem é governado.

As políticas de governo estão articuladas em função de conjunturas, tem institucionalização mais fraca e menor durabilidade e se referem a um projeto específico de forças políticas que assumem o aparelho de Estado e dependem do arranjo de forças e das escolhas políticas.

Romano (apud BARROS, M.; PIMENTEL, 2012) apresenta uma interessante análise para esse debate sobre políticas no Brasil, a afirmar que, no que diz respeito ao caso brasileiro, não temos um Estado federativo nem democrático, uma vez que as políticas que ele determina não passam pelas três esferas - legislativo, executivo e judiciário -, e menos ainda pela sociedade civil. Para o autor, o Estado brasileiro, surgido contra a Revolução Francesa, seria uma tentativa de prevenir supostos "desmandos democráticos" advindos das revoluções francesa e americana. Aqui estaria expressa uma idéia antidemocrática, segundo a qual um poder moderador e neutro seria necessário para ajudar a amortecer choques entre os três poderes no Brasil. Romano considera, 
entretanto, que esse poder não é neutro e se tornou prerrogativa do chefe de estado que pelo executivo controla o parlamento e o judiciário. O poder moderador seria do presidente da república, o que confere até hoje aos chefes de Estado poderes ditatoriais: superconcentração das decisões no poder central e maior concentração dos poderes no executivo. Temos, assim, um federalismo estranho, que não permite diversidade nos ordenamentos legais e nas políticas públicas de estados e municípios.

Tal uniformidade normativa, segundo Romano, abstratamente reúne povos, culturas, situações diversas de modo igual, por meio de portarias de saúde e educação, por ex, que regem todo o país de norte a sul. Essa situação vai de encontro à emergência de práticas sociais e políticas transparentes e democráticas, efetivamente, públicas, portanto. Até aqui a noção de público está confundida com estatal. Ora, sabemos que o fato de ser estatal não garante o caráter público das práticas. $\mathrm{O}$ caráter público dos projetos e programas se faz quando expressam interesses coletivos e funcionam em consonância ao bem-estar coletivo, que se opõe ao funcionamento particularizante com seus totalitarismos e individualizações (BARROS, M.; PIMENTEL, 2012).

Encontramos também em Sader (apud BARROS, M.; PIMENTEL, 2012, p. 9) formulações sobre essa temática, segundo as quais o público assumiu formas confundidas com estatal em função de uma ambigüidade da crítica a uma concepção liberal de Estado, "Nação, classe, comunidade foram invocadas para promover renúncias ao plano individual muitas vezes em nome do público, mas na realidade falando em nome do estatal". Historicamente, diz ele, o primado do público representou a expansão dos poderes de intervenção do Estado, na sua capacidade de regular o mercado. As análises do autor nos indicam, assim, que, por definição, o Estado não é público nem privado, mas campo de disputa entre essas duas esferas. Não podemos, sobretudo, reduzir o público ao estatal. Diz ele:

A crítica ao 'estatismo', paralelamente à apologia do mercado, dos espaços privados, da 'sociedade civil', tiveram como principal efeito - além da desvalorização do primeiro (pólo - estatal) em favor do segundo (pólo - privado), - o deslocamento do outro elemento que antes fazia parte integrante da polarização - o público (SADER, 2005, p. 43).

Tal deslocamento acabou favorecendo a exaltação do pólo privado, "desqualificando o Estado e fazendo desaparecer o público" afirma o autor. Assim os dois termos da dicotomia podem ser definidos independentemente um do outro ou ter sua definição centrada num deles, sendo o outro definido por exclusão. O privado passa a ser o não público, e os dois termos são definidos de forma antagônica e mutuamente dependentes. A definição de um termo está vinculada ao outro e ganha sentido por contraposição. "O interesse público é determinado imediatamente em relação e em contraste com o interesse privado e vice-versa" (SADER, 2005, p. 44). Há, aqui, uma diferença essencial na natureza entre público e privado, que seriam elementos contraditórios entre si. O público pertenceria ao grupo, à coletividade, a sociedade global e o privado ao que pertence a seus membros individuais, eventuais grupos minoritários, como a família, por ex. Tal diferenciação pauta-se, portanto, na dicotomia indivíduo-sociedade.

Cabe destacar, entretanto, que o Estado e os governantes não podem ser a única expressão do coletivo, o que seria privatização das políticas. Mesmo porque ao apresentarmos o coletivo como uma pista para a constituição de políticas públicas, falamos de uma impessoalidade que se faz fora da malha que dicotomiza indivíduo e coletivo. É importante destacar o modo como uma política se constitui como pública, pois uma vez que, se ela se integra à máquina estatal, há o risco de uma captura política que pode se desdobrar num aspecto rígido, inflexível.

Por outro lado, o sentido do termo política para além do domínio das máquinas de governo, seria o de atividade humana, que coloca em relação sujeitos, articulando-os segundo regras ou normas não necessariamente jurídicas ou legais. Desloca-se assim a política de um centro de poder (o Estado, uma classe), considerando também seu exercício em arranjos locais, por microrrelações, indicando a direção micropolítica das relações de poder (FOUCAULT, 1979).

Uma política pública, portanto, implica participação social em sua elaboração, planejamento, execução, monitoramento, e ser estruturada e balizada por meio de lutas coletivas e interesses das diferentes dimensões do socius. Essa dimensão pública de uma política se atualiza como rede de relações multivetorializada, exige interferências, transversalidade, cogestão, inclui sujeitos, com necessidades, demandas. Política pública - ao não se restringir à política de governo, modificável ao sabor das ondas administrativas - é instituição coletiva em meio às lutas sociais por outras cidades, por outros modos de fazer andar a vida, por um outro urbanismo.

As políticas públicas são forjadas por um modo de funcionamento capaz de orientar as singularidades para fora da ordem de serialidade e unidimensionamento, e está além do Estado. Esse comum que se constrói numa política pública se constitui como multiplicidade composta por diferenças singulares que encontram na gestão do comum um novo modo de governo (BARROS, M.; PIMENTEL, 2012).

Conforme Barros, M. e Pimentel (2012), comum não é uma identidade, não se confunde com povo, nem é uniformidade como as massas, são as diferenças que se devem comunicar as diferenças e agir em conjunto. Esse comum se faz como rede heterogênea, dispersa, complexa e multidirecional. Coletivo e singularidade não se excluem, singularidade não é sinônimo de individualidade, pois este último é relação do eu com uma realidade transcendente. Então, esse comum se faz não como materialização de forças hegemônicas que tendem a segmentar, individualizar, definir, demarcar, localizar, cerceando conexões de forças minoritárias que tendem a se exercer em outro sentido, se faz por diferenciação e heterogênese.

Essa abordagem, que permeia políticas estatais e de governo, lida com comunidade-indivíduo. Um fazer que se faz público produz um coletivo que trabalha para 
além de si e de suas fronteiras, acolhe e cuida da vidaoutra. Trabalhar com políticas públicas na esteira do que estamos afirmando é construir coletivamente estratégias de transformar para conhecer partindo de semióticas singulares, incluindo diferentes protagonismos. Pensar políticas públicas que ordenam cidades na direção de outros modos de subjetivação, como nos indica Guattari (1992), é fazer aparecer tensões e controvérsias. Indagando-se os pressupostos e crenças, constituindo-se rede, alterando o padrão comunicacional vigente.

Contudo, as políticas estatais, comumente chamadas de políticas públicas, têm funcionado no sentido de efetuar um processo de integração e amortização de tensões de modo a gerir a miséria necessária (OLIVEIRA, 2011). A máquina estatal capitalística tenta integrar a experiência concreta dos coletivos, operando por meio de processos de individualização, segmentarização e interiorização, fortalece o mito de uma democracia representativa que se contenta com direitos sociais homogeneizantes e idealizados. Neste processo as supostas políticas públicas de educação, de saúde e de assistência social são colocadas a operar como dispositivos biopolíticos de gestão da vida (FOUCAULT, 2010), em suas estratégias de inclusão otimizam alguns modos de vida e aniquilam tantos outros; lubrificando o funcionamento da máquina estatal. Assim, vemos as políticas públicas sendo colocadas a operar como dispositivos de regulamentação da vida, de uma vida amesquinhada e resignada à escolha de possibilidades apresentadas pelo Estado capitalístico.

Mas, não é sem tensões e embates que estes processos se efetuam. Como apontam Coimbra, Monteiro e Mendonça Filho (2006, p. 11) "[...] forças coletivas forçando novas formas de expressão" esboçam outras movimentações que interferem nos traçados da cidade, produzem engasgos no funcionamento da máquina estatal capitalística, deslocam as crenças na democracia representativa e formulam indagações para as quais não é possível apresentar fáceis respostas. A crença de que as políticas públicas decorrem das ações estatais invisibiliza as lutas que incidem no governo da vida, nos dispositivos de regulamentação da existência, deslocando-os de suas trilhas.

Os modos de gestão da economia e de distribuição da riqueza socialmente produzida em voga constituíram a cidade como território de passagem de fluxos do capital, como espaço do perigo que deve ser evitado. Neste processo, os trabalhadores, os moradores de rua, as mulheres, os homossexuais, os negros, as crianças, os jovens, os loucos e os desocupados foram alijados da cena urbana em nome de um espaço asséptico desapropriandoos da cidade. Aqui, as políticas estatais têm sido forjadas muito mais como dispositivos de governo da vida que retire os obstáculos à fruição do capital.

E é exatamente esta desapropriação que tem sido uma das estratégias das revoltas ocorridas em 2013: ocupar as ruas! Trata-se, como aponta Harvey (2013), do direito coletivo à cidade que incide nos processos de privatização do espaço urbano, e da vida de modo mais amplo.
Os acontecimentos de junho de 2013 e as indagações que fazem ressoar: o que não tem começo nem nunca terá... ${ }^{2}$

Em junho de 2013 inúmeras manifestações se espraiaram pelo Brasil tendo como alvo as práticas políticas institucionalizadas, o modo de funcionamento precário das políticas públicas, a militarização da vida cotidiana, o esgotamento do modelo de democracia representativa, as alianças entre governo e os interesses capitalísticos, a violência do aparato policial estatal, a condição de vida nas cidades, dentre inúmeras outras pautas. Ou, melhor dizendo, nas palavras de um dos inúmeros cartazes expostos por participantes dos protestos: "É tanta coisa que não cabe em um cartaz".

As revoltas de junho expressaram os gritos do intolerável, recusando os modos de vida delineados como inevitáveis. Nas várias indagações enunciadas os protestos afirmavam que não era "inútil revoltar-se" (FOUCAULT, 2004). Mais de um milhão de pessoas ocuparam as ruas expressando seu descontentamento com o estado de coisas instituído, constituindo o que autores como Braga (2013) nomearam como maior revolta popular da história brasileira. Não podemos deixar de mencionar que estas revoltas estão, de algum modo, conectadas às manifestações que se espraiaram pela Europa, EUA e pelo Oriente Médio em 2011, ainda que cada uma delas tenha suas particularidades. Ainda que nelas também tenha se expressado um nacionalismo que alimenta e conserva modos institucionalizados de vida. Slogans e bandeiras moralistas estiveram ao lado de expressões que problematizavam muitas das evidências que constituem nossa existência, tais como os modos de fazer política (FOUCAULT, 2004).

$\mathrm{O}$ artigo elaborado por Foucault e publicado no Le Monde em 1979 (FOUCAULT, 2004), indagando o sentido ético da revolta das massas, é extremamente apropriado para falar das fagulhas que se espraiaram pelo país na metade dos anos de 2013. Com a ajuda de Foucault vemos que não se trata de determinar um nexo causal, nem mesmo de fixar um ou outro começo que tenha incendiado o rastilho de pólvora, ou ainda de circunscrever de forma objetiva o conjunto de questões que disparou este 'acontecimento-junho'. Nas palavras de Foucault (2004, p. 77):

As insurreições pertencem à história. Mas, de certa forma, lhe escapam. O movimento com que um só homem, um grupo, uma minoria ou todo um povo diz: 'Não obedeço mais', e joga na cara de um poder que ele considera injusto o risco de sua vida - esse movimento me parece irredutível. Porque nenhum poder é capaz de torná-lo absolutamente impossível [...]. E porque o homem que se rebela é em definitivo sem explicação, é preciso um dilaceramento que interrompa o fio da história e suas longas cadeias de razões, para que um homem possa, 'realmente', preferir o risco da morte à certeza de ter de obedecer.

Os mega eventos como a copa do mundo e as olimpíadas, com o alto investimento estatal de verbas públicas que tem requerido e as interferências que têm

${ }^{2}$ Trecho de letra da música $O$ que será? (à flor da terra) de autoria de Chico Buarque (1976).

Fractal, Rev. Psicol., v. 28 - n. 2, p. 266-274, 2016 
sido efetuadas de forma verticalizada na vida cotidiana das cidades, somada à higienização étnica e social dos espaços urbanos, a intensificação de uma onda conservadora que acirra racismos, junto de um conjunto de políticas compensatórias forjadas de modo desigual e dos efeitos da agenda neoliberal, acrescido do modo como a vida vem sendo forjada na maioria das cidades brasileiras, constituem apenas uma parte dos inúmeros disparadores deste acontecimento-junho. Como aponta Vainer (2013, p. 38-39), “[...] a cidade negócio se atualiza, quase sempre, através de parcerias públicoprivadas, novas formas de relacionamento entre Estado, capital privado e cidade".

$\mathrm{O}$ direito a uma vida não fascista, o direito à cidade $\mathrm{e}$ à constituição de modos de vida menos aprisionadores atravessou os inúmeros protestos, trazendo novas indagações e expressando novas demandas por políticas públicas, requerendo outros modos de fazer política que a afirme como a arte do dissenso, no lugar do terrível consenso que vem sendo fabricado nas últimas décadas em nosso país.

Ainda que estas revoltas tenham sido desqualificadas pelas mega-corporações, por agentes governamentais, pela mídia e por parte dos chamados partidos de esquerda, que procuraram pautas, lideranças, reivindicações claras e objetivas, e desqualificaram os protestos nomeando-os como badernas protagonizadas pela ação de vândalos, criminalizando movimentos e protestos, a maioria de jovens que compunha as vozes heterogêneas que gritaram e gritam nas ruas brasileiras colocaram o dedo na ferida de nosso tempo presente. Trata-se de ocupar o espaço público e debater os modos de governamentalização da vida que estão em cena.

Neste processo, a indagação acerca dos direitos sociais e políticos e sua materialização em políticas estatais constitui-se como uma questão fundamental, mas que não esgota os enunciados das ruas; afinal a luta "não é por R\$0,20 (vinte) centavos". Estas movimentações pautam o sucateamento da existência e as catracas econômicas, políticas e morais que têm constrangido a existência. Portanto, trata-se menos de indagar o que motiva e o os resultados desses protestos e muito mais ficar atento o que está sendo enunciado. Pois "A melhor maneira de matar um acontecimento que provocou inflexão na sensibilidade coletiva é reinseri-lo no cálculo das causas e efeitos. Tudo será tachado de ingenuidade ou espontaneismo, a menos que dê "resultados concretos" (PELBART, 2013, p. 1).

Os acontecimentos de junho colocam em pauta o modo de vida nas cidades, os modos de fazer política e o sentido biopolítico das políticas estatais. As demandas não se encerram em mais políticas de educação, saúde, moradia, transporte, etc., ainda que não as negue. Mais que movimentos reivindicatórios se tratam de movimentos desejantes que recusam uma vida seqüestrada nas malhas do funcionamento atual do capitalismo, do empreendedorismo social desta vida reduzida a um capital humano. ${ }^{3}$

${ }^{3}$ A teoria do capital humano foi delineada nos EUA ao final dos anos 50 por Theodore Schultz. Seu pressuposto é de que os recursos humanos são uma
Nossa indagação e curiosidade situam-se, exatamente, em acompanhar as interferências que tais revoltas têm efetuado nos modos institucionalizados de fazer política e nos modos de compreender os direitos sociais e políticos. Problematizar o modo como temos lidado com os direitos sociais e políticos parece importante para nos retirarmos de um compasso de espera que acredita que apenas a implementação destes direitos já constituídos é ferramenta de afirmação da vida. Não se trata de indignação fraca, ou como dizia Foucault (2010), a santa indignação dos governados, tão suportável para os governos e governantes da vida que se outorgam o direito de falar e delinear o que seriam os nossos problemas. Trata-se de interferir no modo de funcionamento das políticas, no regime de enunciação e fabricação dos direitos, nas obediências às restrições que estes mesmos direitos anunciam em suas cartas de deveres e intenções.

Um deslocamento parece emergir nas revoltas de junho e que diz respeito à enunciação quanto aos direitos e às políticas públicas. Não parece tratar-se aí de reivindicação de políticas para todos, de direitos para todos, pautados em identidades fixas e imutáveis. Essas revoltas têm criado desvios importantes, apontando que já não mais se pode e quer contentar com a integração prometida pelos governantes. Como diz Lazzarato (2006, p. 216), "Não se trata de dizer: "nós temos direito a isso porque somos aquilo", mas sim "nós temos direitos a isto para nos tornarmos outra coisa".

\section{Referências}

ARAÚJO, R. M. B. A vocação do prazer. Rio de Janeiro: Rocco, 1993.

BARROS, M. E. B.; PIMENTEL, H. H. C. Políticas públicas e a construção do comum: interrogando práticas PSI. Polis $e$ Psique, Porto Alegre, v. 2, n. 2, p. 3-22, 2012.

BARROS, R. D. B.; PASSOS, E. Por uma política de narratividade. In: PASSOS, E.; KASTRUP, V.; ESCÓSSIA, L. (Org.). Pistas do método da cartografia: pesquisa-intervenção e produção de subjetividade. Porto Alegre: Sulina, 2009. p.131149.

BENCHIMOL, J. L. Pereira Passos: um Haussman tropical. Rio de Janeiro: Biblioteca Carioca, 1992.

BOBBIO, N. et al. Dicionário de politica. 12. ed. Brasília: $\mathrm{UnB}, 2002.2 \mathrm{v}$.

BRAGA, R. Sob a sombra do precariado. In: MARICATO, E. et al. Cidades rebeldes. São Paulo: Boitempo/Carta Maior, 2013. p. 79-82.

CHICO BUARQUE. O que será? (à flor da terra). Intérpretes: Chico Buarque e Milton Nascimento. In: CHICO BUARQUE. Meus caros amigos. [S.1.]: Phonogram/Philips, 1976. 1 disco sonoro. Lado A, faixa 1.

CHOAY, F. O urbanismo. Tradução de Dafne Nascimento Rodrigues. São Paulo: Perspectiva, 1965.

forma de capital. Assim, o trabalho humano quando é qualificado por meio dos processos de escolarização redunda em aumento de produtividade e em ampliação das taxas de lucro do capital. Tal aumento de produtividade redundaria, para os adeptos desta teoria, em melhoria das condições de vida. O capital humano diz respeito ao total de investimentos que um sujeito ou uma nação fazem visando retornos futuros (FRIGOTTO, 2008). 
COIMBRA, C.; MONTEIRO, A. MENDONÇA FILHO, M. Estado democrático de direito e políticas públicas: estatal é necessariamente público? Psicologia \& Sociedade, [online], v. 18, n. 2, p. 7-12, maio/ago. 2006. Disponível em: <http://www. scielo.br/pdf/psoc/v18n2/01.pdf>. Acesso em: 12 abr. 2015.

DAVIS, M. Planeta favela. São Paulo: Boitempo, 2006.

FOUCAULT, M. Microfisica do poder. Rio de Janeiro: Graal, 1979.

FOUCAULT, M. A verdade e as formas jurídicas. Rio de Janeiro: Nau, 1996.

FOUCAULT, M. Em defesa da sociedade. São Paulo: Martins Fontes, 1999.

FOUCAULT, M. É inútil revoltar-se? In: MOTTA, M. B. (Org.). Ética, sexualidade, política. Rio de Janeiro: Forense Universitária, 2004. Coleção Ditos \& Escritos, v. 5, p. 77-81.

FOUCAULT, M. História da sexualidade: a vontade de saber. Rio de Janeiro: Graal, 2009.

FOUCAULT, M. Os direitos do homem em face dos governos. In: MOTTA, M. B. (Org.). Repensar a política. Rio de Janeiro: Forense Universitária, 2010. Coleção Ditos \& Escritos, v. 6, p. 369-370.

FOURQUET, F.; MURARD, L. Los equipamientos del poder: ciudades, territórios e equipamientos colectivos. Barcelona. Guatavo Gili, 1978.

FRIGOTTO, G. Capital humano. In: PEREIRA, I. B.; LIMA, J. C. (Org.). Dicionário da educação profissional em saúde. Rio de janeiro: Fundação Oswaldo Cruz/Escola Politécnica de Saúde Joaquim Venâncio, 2008. p. 66-72.

GUATTARI, F. Caosmose: um paradigma estético. Rio de Janeiro: Ed 34, 1992.

HARARI, I.; CRISTI, A. Pobres são mais atingidos pela poluição urbana. Carta Maior, [online], 2 ago. 2012. Disponível em: $\quad<$ http://cartamaior.com.br/?/Editoria/Politica/Pobressao-os-mais-atingidos-pela-poluicao-urbana-diz-medico-daUSP/4/25595>. Acesso em: 25 jan. 2015. Entrevista com Paulo Saldiva.

HARVEY, D. A liberdade da cidade. In: MARICATO, E. et al. (Org.). Cidades rebeldes. São Paulo: Boitempo/Carta Maior, 2013. p. 27-34.

LAZZARATO, M. As revoluções do capitalismo. Rio de Janeiro: Civilização Brasileira, 2006.

MIZOGUCHI, D. H. Equivocidades: passagens entre pensamentos. In: BAPTISTA, L. A.; FERREIRA, M. S. (Org.). Por que a cidade? Escritos sobre a experiência urbana e subjetividade. Niterói: EDUFF, 2012. p. 53-64.

NADER, G. Violência e cidadania. Porto Alegre: Sérgio Antonio Fabri, 1994.

OLIVEIRA, C. M. C. de. Atenção básica na assistência social: entre miséria necessária, artes de governar e redes de solidariedade. 2010. Dissertação (Mestrado em Psicologia Institucional) Programa de Pós-Graduação em Psicologia Institucional, Universidade Federal do Espírito Santo, Vitória, 2011.

OTÁVIO, R. Justiça do Rio estuda suspensão das obras no morro da Providência. Carta Maior, [online], 4 set. 2012. Disponível em: $\quad<$ http://cartamaior.com.br/?/Editoria/Direitos-Humanos/ Justica-do-Rio-estuda-suspensao-das-obras-no-morro-daProvidencia\%0D\%0A/5/25898>. Acesso em: 25 jan. 2015.
PECHMAN, R. M. (Org.). Olhares sobre a cidade. Rio de Janeiro: UFRJ, 1994.

PELBART, P. Anota aí: eu sou ninguém. Folha de São Paulo, [online], 19 jul. 2013. Disponível em: <http://folha.uol.com.br/ fsp/opiniao/119566-quotanota-ai-eu-sou-ninguemquot.shtml>. Acesso em: 28 out. 2016.

SADER, E. S. O público, o estatal e o privado. In: HEIMAN, L. S.; IBANHEZ, L. C.; BARBOZA, R. (Org.). O público e o privado na saúde. São Paulo: Hucitec, 2005. p. 43-56.

TELLES, V. S. A cidade nas fronteiras do legal e ilegal. Belo Horizonte: Argvmentvm, 2010.

VAINER, C. Quando a cidade vai às ruas. In: MARICATO, E. et al. Cidades rebeldes. São Paulo: Boitempo/Carta Maior, 2013. p. 35-40.

Recebido em: 11 de setembro de 2015

Aceito em: 7 de julho de 2016 